\title{
Doctor to doctor: getting on with colleagues
}

\author{
Antony Garelick \& Leonard Fagin
}

Abstract Doctor-to-doctor relationships are explored. The impact of the employing organisation on working relationships is considered and methods of analysing problems at the organisational and individual level are described. The application of psychodynamic and systems theory in deepening understanding is discussed, illustrated by vignettes from the work situation. The impact of changes in the work environment are considered and potential sources of support listed.

This is the first of three articles by Garelick $\mathcal{E}$ Fagin exploring working relationships between colleagues in the mental health field. The other two will consider doctor-nurse and doctor-manager interactions.

The customary format for a learned article is to start with a brief review of the literature. Interestingly, in the area of working relationships between medical colleagues there is no significant relevant literature other than in primary care settings, where problematic issues between general practitioners in partnerships have been explored (Newton et al, 1996; Huby et al, 2002). There may be two obvious and non-exclusive reasons for this: first, that doctors consider this a taboo subject, too uncomfortable to delve into, and second, that a mythology of harmonious relationships is being perpetuated by us and by the public.

How important is it to get on ${ }^{1}$ with colleagues? The jobs we do are disparate, encompassing diverse practices undertaken by very different individuals working in a variety of different environments. It is possible that some medical disciplines do not require a great deal of effort expended in this area, as long as one is doing a competent job and patients' needs are being met. But one would be hard pressed to find another medical discipline in which relationships with colleagues are as important as in psychiatry, where clear communication and emotional interaction have such a central role in practice. The subject of getting on with peers,

1. In this article, we intend 'getting on' to mean having a relationship style that allows and ensures its continuance by establishing a pattern of interaction which deals with ongoing issues and conflicts and promotes the achievement of its objectives (task-oriented, leisure, enjoyment, friendships, libidinal, etc.). however, does not figure prominently in undergraduate curricula or when doctors are appointed. Equal opportunities policies, which confine what may be explored at interview, militate against this being discussed openly.

We are unlikely to get on well with everybody all of the time. Friction and disagreement between colleagues inevitably occur at some time. The issue, surely, is whether, in Winnicottian terms, we can get on 'well enough', i.e. be supportive while acknowledging a colleague's individuality and limitations (Winnicott, 1982). The reality is that colleagues of all disciplines are interdependent, and both the service and our professional survival rely on good relationships.

The word colleague comes from the Latin collega, meaning partner in office, which itself is from col- 'together with' and legare, 'depute' (New Concise Oxford Dictionary). 'Profess', from which 'professional' derives, has its origins in Middle English, when 'to be professed' meant to be received into a religious order. By the 17 th century, the meaning had progressed to include the professing of friendship or attachment and the declaration of faith or allegiance to a religious principle. It further evolved over time, to indicate identification with the status of an expert or someone proficient in an area of knowledge and its application to the affairs of others. Embedded in the evolution of these terms are the concepts of faith, allegiance and vocation, and it is only much later that 'profession' becomes associated with such worldly matters as occupation, trade, livelihood and money. These are not simply semantic considerations. Words can express conceptual developments and, in this context, an assumption that allied professionals are attached by common aims and aspirations: this assumption

Antony Garelick is Associate Dean of MedNet and a consultant psychiatrist in psychotherapy for the Tavistock \& Portman and North East London Mental Health Trusts (Tavistock Clinic, 120 Belsize Lane, London NW3 5BA, UK. E-mail: AGarelick@tavi-port.nhs.uk). Leonard Fagin is a consultant psychiatrist and Clinical Director of the North East London Mental Health Trust. 
might underpin a possible mutual reluctance to look at the reality of doctor-doctor interaction and to carry out a critical examination of the idealised myth of harmonious professional relationships.

Consideration of what we mean by getting on needs to be viewed from the perspective of how organisations and their institutional arrangements have changed over time. At one end of the spectrum are the totalitarian organisations that brook no dissent. Conformity is mandatory and getting on other than by submitting to corporate demands is not a possibility. As society and social structures become less authoritarian, the issues of individual expression and interpersonal relationships hold more sway. In essence, not to get on with someone requires that there is enough freedom in the system to allow dissent and disagreement. At the other end of the spectrum, the complete lack or removal of structures of authority can result in anarchy and civil disorder.

\section{The working environment}

Fundamental to working relationships within and between any professional group is the health of the organisations in which they work (Obholzer \& Roberts, 1994). A dysfunctional organisation projects its difficulties onto the service (just as a clinician can project difficulties onto patients) and exacerbates personal and professional tensions. A familiar scenario is the unfair attribution of failure to meet an organisational target to a particular unit or individual. A healthy organisation mitigates these difficulties by being able to provide an emotionally safe-enough environment. Central to this endeavour is a clearly located and accountable authority with a clear focus on its primary task (Stokes, 1994), which in our case is that of providing a good clinical service.

Clearly, not everybody is equally endowed with the capacity to get on with colleagues. This aptitude is closely related to the ability to establish trusting relationships, and this is usually developed in early childhood and is dependent on good-enough parenting. It is a personally subjective state and there is a great variation in individuals' capacity to tolerate conflict and difference. It also has a temporal dimension. Colleagues may initially not see eye to eye, but in time are able to achieve some sort of working arrangement. Needless to say, this can also work in the reverse. Usually, there are a number of factors that encourage positive working relationships to develop, and some of these are listed in Box 1.

The two paradigms that are helpful in our understanding of the phenomenon of getting on are
Box 1 Factors that encourage good working relationships

- Clarity about the organisation's tasks and objectives

- Clarity about the authority structure, with clear lines of accountability

- The presence of a common goal or objectives

- The opportunity to participate and contribute

- The ability to trust and compromise

- The possibility of setting aside inessential differences

- Respect for alternative viewpoints

- Protection of the weakest member of the team

- Good leadership

- A balance between individual aspirations and corporate needs

- Sharing similar life experiences or cultural background

those of the family and of groups. Most of the interpersonal issues that arise occur in those settings (Fagin, 1996). For example, 'sibling relationships' tend to arise between colleagues of similar seniority, whereas 'parent-child relationships' are more likely to emerge between colleagues of disparate seniority, when authority is held by one side over the other.

\section{Relationships between senior medical colleagues}

Patterns and styles of interaction with colleagues will vary according to the context and the task at hand. A committee meeting is likely to follow a formal protocol, but different attitudes and approaches are needed for clinical discussions about a difficult patient, asking a colleague for a clinical view and advice, arguing differences of opinion regarding boundaries of responsibility, being appraised or the subject of a formal complaint, or simply turning to a colleague for informal support at times of pressure. These different contexts demand considerable flexibility and tolerance, and the ability to move from one to another will increase with experience. We are likely to have some measure of control over the conditions in which they occur, as well as the appropriate language to use in each circumstance. Sometimes, although clearly not always, we can select different people to engage in some of these interactions.

The areas in which relationships between senior colleagues are most likely to be put under strain can be divided into organisational factors (Box 2) and personal characteristics and factors (Box 3). 
Box 2 Organisational factors that strain relationships with senior colleagues

- Competition for scarce resources

- Consultants fighting for their own patch and their share of financial or professional support

- Inequality of case-loads and responsibilities

- Problems associated with territory and boundaries, particularly when these are poorly defined

- Relationships with the clinical and medical directors

- Differences in rates of pay for similar jobs

- Institutional discrimination

\section{Consultants getting on with juniors}

The relationship between consultant and junior is obviously affected by the difference in power and status. Consultants need to accept that their main task in this interaction is to be good-enough role models and to create an environment in which trainees can most effectively gain in skills and knowledge. Consultants have multiple roles in this interaction: trainer, supervisor, boss and reference provider. They are responsible for ensuring that juniors are not overwhelmed by their case-loads and by the emotional aspects of working with difficult patients. They also have to struggle with the need to

Box 3 Personal characteristics and factors that strain relationships with senior colleagues

- Competitiveness (promotion, merit awards, salaries and national recognition)

- Quality of leadership

- Inability to deal with anger in a constructive fashion

- Different therapeutic approaches to clinical work

- Team players $v$. individualists

- Thinkers $v$. doers

- Innovators $v$. conservatives

- Optimists $v$. pessimists

- Prejudice $v$. tolerance

- Joiners-in $v$. loners (cabals, cliques and permanent outsiders)

- Controllers v. delegators

- Quick responders v. prevaricators

- Thick- $v$. thin-skinned individuals ensure that service demands are being adequately met, but that juniors are not being exploited. Most consultants will be trying to encourage their juniors' interest in the subject by using their experience and knowledge, but they must be aware of how they convey their emotional state if they themselves are feeling overwhelmed and stressed by their work. Having a keen, bright-eyed, inquisitive, challenging and hard-working junior can make the consultant's task a pleasurable one, but a 'difficult junior' is another matter.

\section{Getting on with the difficult junior}

This is a complicated and extensive area, and it is not possible to do it justice in this short article. Boundary issues are very important, particularly if the junior's personal problems, which may or not be identified during supervision, are re-enacted in the working relationship and affect their functioning. In the 6 months available, consultants have to focus on common tasks and aims, but this often leaves them wondering whether to support or chastise a junior who is not coming up to the mark. It is obviously important to recognise that many juniors are still very inexperienced (and that seniors were once in their shoes), and that taking a longer view may allow consultants to identify potential areas for development and ways to strengthen positive aspects. Consultations with the clinical tutor can be very helpful here. Box 4 shows some common problem areas that junior doctors present to their consultants.

The parent-child paradigm we discussed above reflects the need for seniors to act, to some extent, in loco parentis. They need to be patient and tolerant of

\section{Box 4 The problem junior}

- The junior who is not sure that psychiatry is the right choice

- The junior who does not do what is asked

- The grandiose junior who already 'knows everything'

- The dependent junior who wants to be looked after and cannot make any decisions

- The junior who attempts to establish an exclusive relationship, is hypersensitive to exclusion and exhibits rivalry with other team members

- The anxious junior

- The principled, combative junior

- The idolising or flattering junior

- The flirtatious junior

- The paranoid junior 
inexperience and to protect their juniors from the hazards of emotional vulnerability and extensive case-loads. At times, however, seniors have to advise juniors that they should reflect on changing their choice of specialty if it is clear that there are major areas of difficulty.

\section{Juniors getting on with consultants}

An essential element in the junior-consultant relationship is that the junior shows interest in the subject, maintaining curiosity and inquisitiveness. It is permissible, and even encouraged, for juniors to show inexperience, anxiety and doubt, but their ability to do this obviously depends on how safe their relationship with their consultant feels. The responsibility for creating this sense of security is mutual, so juniors must not feel that they are completely passive agents in this process. For example, supervision sessions offer 'quality time' with a senior, and the junior can accrue considerable dividends by carefully preparing for them in advance.

The problem of relationships in this area is not helped by the rotational system: although it presents juniors with a variety of experiences, placements tend to be too short for either side to notice personal development and they inevitably place individuals in areas for which they have little or no affinity. The importance is to recognise this difficulty, talk about it and make the best of the experience. There is always something useful to learn, even if that sub-specialty may not be a long-term goal. When the chemistry works, juniors will recognise the enthusiasm that consultants can invest in their apprenticeship and their career aspirations, but when the relationship is poor, juniors face considerable obstacles.

\section{Getting on with the difficult consultant}

Differences in power and status, and dependence on references for further career advances, sometimes place juniors in invidious positions when they experience problems in their relationships with their trainers. Recent surveys suggest that bullying of juniors is more frequent than we would like to think (Quine, 2002; Paice \& Firth-Cozens, 2003). Occasionally, these difficulties can be openly discussed and addressed, but more often than not, the subject becomes a matter for private discussions between fellow peers or, at best, can be brought up with the clinical tutor. The clinical tutor then has to decide on the appropriate course of action, bearing

\section{Box 5 The problem consultant}

- The authoritarian, bullying consultant

- The indecisive and disorganised consultant

- The controlling consultant, who has difficulties delegating

- The burnt-out consultant

- The consultant who is never there

- The consultant who is biding time to retirement

- The flirtatious consultant

- The poor teacher and communicator

in mind that the junior's welfare and training are the primary concern. Corridor gossip will affect, whether justifiably or not, a junior doctor's placement choice.

Box 5 shows some of the difficult consultant types that juniors face.

\section{Juniors getting on with juniors}

Problems between junior colleagues are likely to emerge when personality issues interfere with cooperative working arrangements. Some classic issues of dispute are shown in Box 6 .

The period spent in training often brings opportunities to establish lifelong bonds of friendship, which can be of great benefit for future careers. Likewise, sharing considerable time during meals and evenings on-call make it not unlikely that intimate relationships will ensue. If this situation arises, it can be a problem if handled poorly.

Life as a junior, particularly in hard-pressed acute care environments, can be very stressful, especially for those who are inexperienced or emotionally vulnerable. For many, the first port of call for support is a slightly more experienced junior colleague, who knows the ropes and does not have the status of seniority and distance as a handicap.

\section{Box 6 Areas of friction between juniors}

- Duty rotas

- Leave entitlements and choice

- Covering for others during periods of absence

- Leaving patients to be clerked by the next shift

- Competition for sought-after posts

- A pecking order determined by experience differentials 


\section{How do we deal with problem relationships?}

\section{The impact of clinical work}

It is well recognised that the individual psychopathology of a patient can be a powerful factor in the interprofessional relationship (Temple, 1999). Polarisation of the staff's attitudes towards a patient (splitting - see below) is a common occurrence. Among doctors this is frequently encountered between the junior doctor and the consultant.

\section{Vignette 1 \\ Mrs A was admitted with depression and suicidal thoughts. She had felt consistently traumatised in her upbringing by an unpredictable and volatile mother who used to lash out. Mrs A evoked considerable sympathy in a junior doctor and began to talk through these issues with him. However, the junior did not know that she was also expressing increasing anxiety about deliberate self-harm to the nursing staff, who conveyed their concern to the consultant. As a result of this, the consultant changed the clinical programme. The junior doctor was left feeling explosively angry towards the consultant. This situation was resolved in clinical supervision conducted by a colleague from outside the clinical team.}

An awareness of defence mechanisms such as splitting (the division of an object (person) into separate good and bad persons as a method of coping with conflict and anxiety) and the concept of transference (which describes the way in which we relate to the world on the basis of crucial past relationships) (Hughes \& Kerr, 2000) is important. These ubiquitous unconscious processes can, if not identified, have powerful disruptive effects on interprofessional relations. The dynamic of the splitting of staff engendered by Mrs A in the above vignette was creatively explored during the external clinical supervision, enabling greater clinical understanding. This reflective practice avoided a potentially damaging conflict between the junior and senior doctors (Main, 1957).

A psychodynamic perspective is helpful in dealing with the recognition of how a patient's individual psychopathology may be enacted in interprofessional relationships. The majority of these interactions take place unconsciously. This is, of course, also true at the organisational level (Halton, 1994).

\section{Non-clinical interactions}

Doctors have to have strong personalities and the determination necessary successfully to train in and to practise medicine. So it is not surprising that among this group of strong-willed, intelligent, highly educated professionals there will be conflicts. Doctors are very focused on treating their patients, but they do not have a good track record for looking after themselves (Firth-Cozens \& Payne, 1999). This particularly applies in the doctor-doctor relationship in the work setting.

The majority of difficulties in this area can be dealt with by using common sense, maintaining a sense of perspective and balance, and staying in touch with the fact that we are all fallible human beings. Work is just one part of life. Humour, sensitivity, the capacity to view things from a colleague's perspective (empathy) and timing are all important and helpful attributes. Informal exchanges over coffee, and even well-intentioned gossip, are important ways in which we manage relationships. The majority of day-to-day frictions and irritations can be dealt with in this way. It is therefore important to ensure that there is sufficient unstructured time for this to take place.

Continuing and thornier problems need more structure in order to address them. A meeting with the peer group or with an impartial and respected senior clinician or facilitator, carried out in a 'safe' place and with respect for confidentiality, offers an arena in which problems can be aired and, hopefully, resolved.

Vignette 2 The newly appointed consultant A new post-holder, after a honeymoon period, complained to the clinical director that the catchment area was organised in such a way that the senior consultant for the patch had the most affluent population, which had a lower morbidity. The young consultant felt unable to challenge his senior colleague, a situation complicated by the fact that the senior consultant was also his mentor. The senior for his part said that he had been coping with the whole catchment area for 15 years and it was now time for the junior colleague to take on a considerable amount of the clinical load so that he could proceed to other management issues and research.

This was dealt with by informal collective peer group discussion, a compromise was eventually reached and the new consultant was allocated some additional clinical resources.

Problems of great severity require formal consideration that is likely to involve the clinical or medical director. These individuals face the constant problem of being pulled in different directions, with pressure to identify with management at the expense of colleagues and vice versa. The capacity to resist these pressures is critical for the successful undertaking of their role, fulfilling a complex task in management while remaining clinicians and members of their peer group (Oldham, 1996). At such 
times it is important to have agreed parameters with clear points of reference, whether they be constitutional or contractual, while keeping a focus on the common aims and the primary tasks that all clinicians are employed to deliver. Critical to addressing problems is the ability to stand back and analyse them.

Paradoxically, although psychiatrists undertake an extensive training that includes psychology, psychotherapy and a broad range of therapeutic strategies, when it comes to dealing with difficulties with colleagues our professional skills are frequently not evident. Although it is important not to pathologise difficulties, individuals need to be able to reflect on these issues and to carry out critical self-appraisal.

A fundamental subject to consider in conflict resolution is the interrelationship between the working environment, the individual concerned and the health of the organisation. Although it is not always the case, often what are apparently purely personal problems are in reality the symptoms of underlying and unresolved organisational problems.

Vignette 3 Low morale

A pervasive sense of dissatisfaction and disengagement had infiltrated a consultant group. This was expressed by poor attendance at joint meetings, unwillingness to meet and discuss issues of common interest and rumours that some consultants were looking for jobs elsewhere. There was a pervasive feeling of unhappiness.

An independent outside facilitator met with the peer group on an away-day located off site. This enabled the airing of frustrations and the beginning of a more constructive dialogue. The use of a safer, more neutral space was of critical importance.

A familiarity with systems theory as applied to families, groups or organisations is helpful in this regard. Organisational dynamics tend unconsciously to push forward a predisposed individual as spokesperson, expressing previously unspoken difficulties on behalf of everybody else. Not unusually, this person ends up as the scapegoat. It is therefore wise to look at an apparent personal problem as potentially providing intelligence about organisational dilemmas (Stokes, 1999).

The spokesperson who unconsciously expresses views on behalf of everybody can be understood in terms of group processes and by the mechanism of projection. We have already discussed how predisposed individuals can be particularly receptive to the projections of the group and how the group's common problems or anxieties can become externalised and located in a particular person. This process is similarly conceptualised in systems theory, when individuals assume a particular function for the group or family. This state of affairs can be perpetuated by the dynamics and needs of the group. It is important in this situation to question the what, why, when, who and how of the 'symptom':

- What is the problem?

- What function might it serve?

- What is the context?

- Why is it present?

- Why now?

- Why this particular phenomenon?

- When is it present? When did it start? When is it worse, when is it better?

- Who has the problem?

- How does the problem affect everybody else?

This approach is used in family systems therapy and it can be helpful when trying to discover the actual nature of the difficulties that arise in working relationships (Asen et al, 2003).

Sometimes those involved in problems that arise in the medical workplace are so entangled with the issues that it is necessary to arrange for an external consultancy. This should not be undertaken lightly, care being taken that the chosen individual is appropriately skilled and independent. A pitfall to be avoided is the imposition of an external consultant who acts as a mouthpiece for a particular view held by the organisation (the 'management') (Huffington et al, 1997). This can be particularly undermining of staff morale.

Vignette 4 Territorial battles

Two fairly comparable clinical services within the same trust were believed to have different outcomes, as well as different levels of satisfaction from users. This prompted management to praise the one service and raise it as its flagship, while treating the other as the sick member of the trust and planning remedial action, with regular interventions from outside consultants. In this environment the consultants in the favoured sector secretly criticised the practices of the other, while the consultants in the other sector felt that they had been unfavourably treated in terms of resources and facilities. None of these views was openly expressed.

This eventually led to a request for an independent organisational consultation, which identified a number of complex factors, including problems in management that accentuated the drive to find a scapegoat for the 'sick' service's difficulties.

It is important to bear in mind that not all problems can be solved. Some people are very talented in a circumscribed area, but are extremely difficult to work with. There will always be appointments that turn out to be failures, or cause problems or create a clash of personalities. A healthy management and 
organisation can mitigate some of these difficulties by trying to support the strengths of each individual, containing difficult or even destructive features of their personalities and, by using flexibility and imagination, attempting to fit each person into the organisation in the least abrasive way possible.

\section{The changing environment}

The workplace environment is changing very rapidly, as is society's view of doctors. The notion that the doctor is always right, underpinned by a mutual fantasy of idealisation (which relieves the patient of anxiety and responsibility), has long passed, as has the patient's passive acquiescence to the doctor. As perceptions of clinicians' fallibility become more prevalent and publicised, doctors are increasingly having to earn their patients' respect, rather than relying on their automatic trust. Society is much more questioning of its professionals, and concerns are increasingly expressed about whether therapeutic interventions will work and about the limitations in competence and performance of individual practitioners. Simultaneously, there is the demand for ideal, risk-free treatments. We have clearly moved from an unregulated world in which the doctor was idealised to an environment of scrutiny and revalidation. The ingredients of clinical governance, audit, clinical effectiveness, evidencebased medicine, research management, quality assurance, personal development and revalidation - all part of the brew of personal appraisal and continuous professional development - will undoubtedly have an impact on doctor-to-doctor relationships. As with any change, these new factors in the doctor's working environment tend to provoke polarised reactions: some clinicians are hostile and feel persecuted, others see only benign, potentially helpful advances. What is critical is how new initiatives are implemented, as this will reflect not only on the individuals, but also on the health of the organisation in which they work. The jury is still out on whether these new ideas will overload an already overstretched professional group or will protect them from overwork and potential burnout. The best approach is to look for the positives in these changes and to try to maximise them. It is important that doctors grasp the opportunities on offer, think about their practice and working relationships, receive feedback and have time for further study.

\section{Potential sources of support}

An increasing number of structures and organisations offer support to doctors and recognise the various stresses that are part of their working life

\section{Box 7 Potential sources of support}

- Mentorship for newly appointed consultants

- Peer reference groups for personal development plans (in practice, these groups can also provide informal peer support)

- Informal buddies

- Clinical directors and medical directors

- Appraisal conducted as a supportive, enabling exercise

- Medical committees

- The British Medical Association (advice and counselling service)

- The Royal College of Psychiatrists

- Local deaneries: some provide a confidential self-referral service for doctors with psychological problems, e.g. the London Deanery's MedNet at http://www.londondeanery. ac.uk/MedNet/index.asp

(Box 7). Some are formal, some informal, and the boundaries between them are ill defined. But regardless of their set-up, it is important that doctors feel comfortable enough to turn to them when necessary (Paice et al, 1999; Ikkos, 2000). Finally, in Box 8 we summarise the golden rules to remember when faced with problems in working relationships with medical colleagues.

Difficulties in getting on with colleagues are part of human experience. They are like weeds in a garden: with constant attention we can reduce them to an acceptable level, but we cannot totally remove them (A. Obholzer, personal communication, 2003).

\section{Box 8 The golden rules for dealing with} problem working relationships

- Think first: put yourself in the other's shoes - empathise

- Do not underestimate the value of a quiet chat, informal discussion or benign gossip

- Consult a colleague who is not involved and whom you can trust

- Do not feel that you have to deal with everything alone: remember the value of sharing a problem

- Be prepared to use formal structures, medical committees, clinical directors and outside agencies

- Do not avoid the issue: after all, a stitch in time saves nine

- Learn from your mistakes

- Make a list of helpful agencies that you can consult 


\section{References}

Asen, E., Tomson, D. \& Tomson, P. (2003) Ten Minutes for the Family: Systemic Practice in Primary Care. London: Routledge.

Fagin, L. (1996) Teamwork among professionals involved with disturbed families. In Collaborative Community Mental Health Care (eds M. Watkins, N. Hervey, J. Carson, et al). London: Arnold.

Firth-Cozens, J. \& Payne, R. (1999) Stress in Health Professionals: Psychological and Organisational Causes and Interventions. Chichester: John Wiley \& Sons.

Halton, W. (1994) Some unconscious aspects of organisational life. In The Unconscious at Work: Individual and Organizational Stress in the Human Services (eds A. Obholzer \& V. Z. Roberts). London: Routledge.

Huby, G., Gerry, G., McKinstry, B., et al (2002) Morale among general practitioners: qualitative study exploring relations between partnership arrangements, personal style and workload. BMJ, 325, 140-144.

Huffington, C., Cole, C. \& Brunning, H. (1997) A Manual of Organisational Development. London: Karnac.

Hughes, P. \& Kerr, I. (2000) Transference and countertransference in communication between doctor and patient. Advances in Psychiatric Treatment, 6, 57-64.

Ikkos, G. (2000) Responding to trainee doctors in difficulty. Hospital Medicine, 61, 348-351.

Main, T. (1957) The ailment. British Journal of Medical Psychology, 30, 129-145.

Newton J., Eccles, M. \& Soutter, J. (1996) General practice partnerships: an exploratory review. Journal of Management in Medicine, 10, 62-71.

Obholzer, A \& Roberts, V. Z. (1994) The Unconscious at Work: Individual and Organizational Stress in the Human Services. London: Routledge.

Oldham, J. (1996) Consultants and clinical team management. Advances in Psychiatric Treatment, 2, 226-231.

Paice, E. \& Firth-Cozens, J. (2003) Who's a bully then? BMI 326, 73-93.

Paice, E., Orton, V. \& Appleyard, J. (1999) Managing trainee doctors in difficulty. Hospital Medicine, 60, 130-133.

Quine, L. (2002) Workplace bullying in junior doctors: questionnaire survey. BMJ, 324, 878-879.

Stokes, J. (1994) The unconscious at work in groups and teams. In The Unconscious at Work: Individual and Organizational Stress in the Human Services (eds A. Obholzer \& V. Z. Roberts). London: Routledge.

Stokes, J. (1999) Work. In The Talking Cure (ed. D. Taylor) London: Duckworth.

Temple, N. (1999) Should consultant psychiatrists be trained in psychotherapy? Advances in Psychiatric Treatment, 5, 288-295.

Winnicott, D. W. (1982) Ego distortion in terms of True and False self. In The Maturational Processes and the Facilitating Environment. London: Hogarth Press.

\section{Multiple choice questions}

1 What is the most likely explanation for the paucity of literature on doctor-to-doctor relationships?

a that there are no suitable journals in which to publish

$\mathrm{b}$ confidentiality issues

c an idealised myth of harmonious relationships

d reluctance of doctors to participate in studies

e the absence of an appropriate research methodology.

2 Which is the most important organisational factor in aiding good working relationships?

a a small catchment area

b compulsory management training

c an incentive scheme

d a structured, focused organisation with active participation of its staff

e fixed-term contracts.

3 What are the two mechanisms most likely to generate conflict in the clinical situation?

a splitting

b repression

c denial

d unconscious enactment

e regression.

4 Which of the following can be useful in understanding the vociferous spokesperson in an organisation?

a introversion-extroversion

b systems theory

c Maslow's hierarchy

d projection

e idealisation.

5 What is the most important factor when considering engaging an outside consultant?

a that the person is independent, not acting as mouthpiece for the organisation

$\mathrm{b}$ the professional background of the individual

c immediate availability

d a very structured agenda

e that the person is a Royal College representative.

\begin{tabular}{|c|c|c|c|c|}
\hline \multicolumn{5}{|c|}{ MCQ answers } \\
\hline 1 & 2 & 3 & 4 & 5 \\
\hline $\mathrm{F}$ & a F & a $\mathrm{T}$ & a F & $\mathrm{a}$ \\
\hline $\mathrm{F}$ & $b F$ & b $F$ & $\mathrm{~b} T$ & $b$ \\
\hline $\mathrm{T}$ & c F & c $\mathrm{T}$ & c $\mathrm{T}$ & $c$ \\
\hline $\mathrm{F}$ & $\mathrm{d} \mathrm{T}$ & d F & $\mathrm{d} \mathrm{T}$ & $\mathrm{d}$ \\
\hline $\mathrm{F}$ & e F & e $\mathrm{F}$ & e F & $\mathrm{e}$ \\
\hline
\end{tabular}

